\title{
MENILAI KEPUASAN PELANGGAN KOPI ARABIKA SPECIALTY PT. ORO KOPI GAYO MELALUI HARGA, KUALITAS PELAYANAN, DAN CITRA MEREK
}

Submitted Date :

24 Agustus 2020

Accepted Date :

13 November 2020
Bambang

Universitas Syiah Kuala

sayabambang00@gmail.com

Ansari

Universitas Syiah Kuala

\section{Suggested Citation:}

Fiazisyah, a.(2018). Pengaruh Kualitas Produk, Harga, Dan Kualitas Pelayanan Terhadap Kepuasan Konsumen Restoran Cepat Saji Kfc Basuki Rahmat Surabaya, e-jurnal boga, Volume 7 No. 02, 168-187

\section{Abstract:}

This study aims to determine the effect of price, service quality and brand image on customer satisfaction. with a research population consisting of objects / subjects that have quality and characteristics that are not limited (infinete) determined by the researcher to study a nd draw conclusions as many as 180 questionnaires. This study uses primary and secondary data, this data is collected and analyzed to determine the strength and significance of the relationship between price, service quality, brand image, and customer satisfaction. The results of this study indicate a positive and significant effect on price, service quality, and brand image on customer satisfaction at PT. Oro Kopi Gayo.

Keywords : Brand Image, Costumer Satisfaction, Price, Service Quality

\section{Abstrak}

Penelitian ini bertujuan untuk mengetahui pengaruh harga, kualitas pelayanan dan citra merek terhadap kepuasan pelanggan. dengan populasi penelitian yang terdiri atas objek/subjek yang mempunyai kualitas dan karakteristik yang tidak terbatas (infinete) yang ditetapkan oleh peneliti untuk dipelajari dan ditarik kesimpulannya sebanyak 180 kuisioner. Penelitian ini menggunakan data primer dan sekunder, data ini dikumpulkan dan dianalisis untuk menetapkan kekuatan dan signifikansi hubungan antara harga, kualitas pelayanan, citra merek, dan kepuasan pelanggan. hasil dari penelitian ini menunjukkan pengaruh yang positif dan signifikan pada harga, kualitas pelayanan, dan citra merek terhadap kepuasan pelanggan PT. Oro Kopi Gayo.

Kata kunci : Citra Merek, Harga , Kualitas Pelayanan, Kepuasan Konsumen

JEL Classification : M31 


\section{Latar Belakang}

Perusahaan merupakan salah satu tempat terjadi produksi dan berkumpulnya semua faktor produksi yang menjadi sebuah lembaga yang terorganisir dengan tujuan untuk memperoleh sebuah keuntungan. Perusahaan mempunyai fungsi esensial untuk mencapai suatu tujuan dalam menghasilkan barang dan jasa sehingga para konsumen merasa puas terhadap produk dan jasa yang ditawarkan. Kepuasan konsumen adalah hal yang sangat penting bagi setiap Perusahaan karena ketika konsumen melakukan pembelian terhadap barang dan jasa yang dijual kepada konsumen, maka PT. Oro Kopi Gayo harus mampu memberikan kualitas barang dan jasa yang akan dibeli oleh konsumen.

Menurut Guzzo (2010), Kepuasan pelanggan merupakan suatu tingkat frekuensi pembelian produk dan layanan yang diberikan kepada konsumen sehingga konsumen merasa puas dengan apa yang mereka dapatkan, kepuasan pelanggan timbul karena ada sesuatu yang timbul dari sebuah produk dan mereka menikmati kelebihan itu dari sebuah harapan yang mereka tunggu ketika melakukan pembelian suatu barang dan jasa dan ketika konsumen mampu merasakan umpan balik dari sebuah produk atau jasa maka konsumen akan tidak ragu terhadap harga yang telah ditawarkan kepada konsumen karena harga merupakan nilai dari suatu barang yang diukur dalam bentuk uang yang menjadi alat untuk mendapat kepuasan konsumen dalam mendapatkan produk dan jasa.

Menurut Kotler dan Amstrong (2012), harga merupakan jumlah yang ditagih oleh PT. Oro Kopi Gayo terhadap produk yang telah dibeli oleh konsumen demi mendapatkan keuntungan. Di dalam dunia bisnis, harga sudah sangat mempengaruhi pemasaran di Perusahaan, konsumen selalu memperhatikan naik turunnya harga sebuah produk sehingga harga yang ditawarkan menjadi sebuah pertimbangan konsumen pada saat membeli barang dan jasa, namun ketika perusahaan mampu memberikan kualitas produk yang baik maka konsumen akan sangat puas terhadap produk yang konsumen beli walaupun terkadang harganya terlalu mahal

Dalam menentukan harga, setiap Perusahaan memiliki strategi yang berbeda-beda tapi memiliki tujuan yang sama dalam menghasilkan laba, mencapai pangsa pasar, dan target volume penjualan produk. Dalam menentukan harga produk harus dilakukan sebuah strategi yang sesuai dengan kondisi yang terjadi di Perusahaan yaitu (skimming price) yaitu promosi yang tinggi dan harga barang dan jasa yang tinggi. Di dalam pemasaran produk kita masih perlu melakukan pelayanan yang baik sehingga ketika para konsumen datang untuk membeli produk disaat itulah konsumen merasakan ada layanan yang berikan oleh perusahaan dan konsumen akan merasa puas terhadap layanan yang diberikan mulai dari ketanggapan, kehandalan, jaminan dan empati sehingga pelayanan yang diberikan mempunyai kepuasan tersendiri bagi para konsumen.

Menurut Schnieder \& White (2004) kualitas pelayanan sebagai perbedaan antara harapan pelanggan dengan layanan yang diterimanya. PT. Oro Kopi Gayo harus dapat memberikan kepuasan kepada konsumen dan memberikan citra yang baik di mata masyarakat dengan cara memberikan pelayan yang berkualitas. Maka, Perusahaan harus berusaha memperbaiki keadaan dengan memberikan pelayanan yang terbaik kepada konsumen, dengan melakukan pelayanan yang baik diharapkan konsumen akan merasa dihargai dan dilayani dan akhirnya pelanggan yang membeli barang dan jasa akan merasa puas.

Perusahaan dituntut untuk meningkatkan kualitas produk sehingga Perusahaan terus melakukan sebuah pergerakan dalam meningkatkan produk yang dimilikinya demi mempertahankan citra merek Perusahaan. Perusahaan yang memiliki citra merek yang baik, maka pelanggan bisa membedakan produk mana yang memiliki kualitas yang baik. Mohajerani dan Miremadi (2012) menjelaskan bahwa citra adalah sebuah kesan yang dibuat dibenak konsumen secara keseluruhan di benak konsumen. Penilaian konsumen terhadap citra merek telah dipengaruhi oleh merek yang digunakan oleh konsumen, sehingga keputusan konsumen saat membeli melibatkan persepsi terhadap layanan dan harga untuk dapat memuaskan pelanggan.

Banyaknya perusahnaan yang telah memproduksi berbagai macam komoditi unggul seperti sawit, kakao dan kopi yang sesuai dengan daerah masing-masing, sesuai dengan hasil pertanian setiap daerah komoditi kopi lebih diprioritaskan untuk diteliti kembali karena banyak konsumen telah menyatakan kopi arabika yang berasal dari dataran tinggi gayo sudah masuk dalam pasar nasional maupun internasional. oleh karena ituPerusahaan pengolahan bubuk kopi mempunyai pasar yang potensial dan sangat bersaing dari segi kualitas rasa, bentuk dan aroma dan merek. Merek-merek Kopi Arabika yang ada di pasar domestik di Indonesia seperti arb coffee, aroma coffee, bumi aceh coffee dan lain-lain Semua merek ini sudah sangat banyak diminati oleh konsumen di Indonesia. Setiap merek ditawarkan melalui pelayanan tersendiri oleh Perusahaannya untuk pelanggannya berupa layanan purna jual, harga murah, produk kopi yang berkualitas, rasa dan aroma yang baik.

PT.Oro Kopi Gayo merupakan salah satu industri yang melakukan pengolahan Kopi Arabika di Aceh Tengah mulai dari hulu ke hilir dan sudah mempunyai produk unggulan yaitu bubuk Kopi Arabika specialty dengan merek Gayo Aceh coffee yang memiliki ciri khas yang unik jika dibandingkan dengan produk kopi merek 
lainnya. Hal ini telah menjadi sebuah keputusan sebuah Perusahaan dalam melakukan pemasaran produk Kopi Arabika, bisa melakukan pemasaran di Luar Negeri atau Negara lain. Maka dari itu, Perusahaan harus meningkatkan kualitas produk yang sesuai dengan harga yang ditawarkan dan merek yang mudah dikenal banyak orang.

Namun banyak hal yang terjadi dalam melakukan pengolahan kopi arabika specialty ini mulai dari hulu ke hilir seperti harga yang mahal yang sangat berdampak pada keuntungan perusahaan dan banyak kejadian yang dilakukan oleh para petani pada saat proses berlangsung apakah sudah sesuai dengan standart operasional prosedur PT. Oro Kopi Gayo terapkan untuk para petani karena semakin baik proses yang dilakukan maka semakin naik harga yang ditawarkan hal ini sangat nyata dialami setiap konsumen ketika melakukan pembelian pasti akan timbul sebuah pertanyaan bagaimana proses yang dilakukan oleh petani supaya konsumen mau membayar dengan harga yang mahal dan sesuai dengan kualitas produk yang ditawarkan. Berkaitan dengan layanan ini sangat berpengaruh pada sikap atau karakter konsumen ketika membeli produk bubuk kopi arabika specialty, PT. Oro Kopi Gayo harus mampu memberikan jaminan, empati dan ketanggapan karena banyak perusahaan tidak mampu memberikan pelayan yang baik dikarena kurangnya maelakuakn pelatihan terhadap karyawannya diharapkan pada PT. Oro Kopi Gayo ini harus melakukan pelatihan terhadap karyawan untuk pembentukan karakter sehingga para karyawan mampu memberikan pelayanan terhadap konsumen yang mempunyai karate yang berbeda-beda.

Banyaknya pesaing dibidang pengolahan Kopi Arabika membuat Perusahaan harus terus mampu untuk berinovasi dengan cepat sehingga Perusahan tidak kalah dalam persaingan produk Kopi Arabika Gayo agar pelanggan merasa puas dan setia terhadap produk yang telah di jual oleh PT. Oro Kopi Gayo, PT. Oro Kopi Gayo dihadapkan dengan pesaing sehingga para konsumen terkadang merasa ragu terhadap merek yang mereka beli, maka dari itu PT. Oro Kopi Gayo harus menjaga kualitas pelayanan yang baik sengan cara meningkatkan fasilitas fisik, perlengkapan, pegawai dan sarana komunikasi, cepat tanggap terhadap pelanggan, memberikan jaminan bahwa produk kopi merek gayo aceh coffee tidak berbahaya untuk dikonsumsi dan mudah dalam berkomunikasi yang baik dan memahami kebutuhan para pelanggan

Perusahan pengolahan bubuk Kopi Arabika sudah sangat berkembang pesat di Kabupaten Aceh Tengah dan Bener Meriah sehingga kualitas dan harga yang ditawarkan juga berbeda-beda. Hal ini akan menjadi sebuah persaingan bagi Perusahaan PT. Oro Kopi Gayo dalam menentukan harga, faktor harga merupakan faktor yang dianggap menarik bagi Perusahaan PT. Oro Kopi Gayo karena setiap Perusahaan yang berada di Kabupaten Aceh Tengah dan Bener Meriah mempunyai harga yang berbeda mulai dari harga terendah hingga harga tertinggi sehingga perusahaan PT. Oro Kopi Gayo sulit untuk mendapatkan keuntungan yang besar. sehingga PT. Oro Kopi Gayo harus membuat daya saing harga, keterjangkauan harga dan kesesuaian harga dengan manfaat yang diterimanya

Adapun tujuan dari penelitian ini adalah untuk mengetahui pengaruh harga yang ditawarkan kepada konsumen serta layanan yang diterima oleh konsumen dan citra merek yang telah dirasakan oleh konsumen ketika melakuka pembelian bubuk kopi arabika specialty PT. Oro Kopi Gayo. Masalah penelitian ini bisa di lihat pada kasus yang telah terjadi di restoran KFC Surabaya yang telah dilakukan sebuah penelitian oleh fiazisyah, (2018) mengenai harga, kualitas pelayanan dan kepuasan konsumen, dimana variabel ini sangat penting untuk di terapakan dalam sebuah perusahaan untuk mempertahankan konsumen dan keuntungan yang berkelanjutan.

Maka dari itu peneliti sangat tertarik untuk meneliti mengenai pengaruh pengaruh harga terhadap kepuasan pelanggan, kualitas pelayanan terhadap kepusaan pelanggan dan citra merek terhadap kepuasan pelanggan PT.Oro Kopi Gayo dan bias kita lihat kerangka penelitian dibawah ini 
Gambar 1. Kerangka penelitian

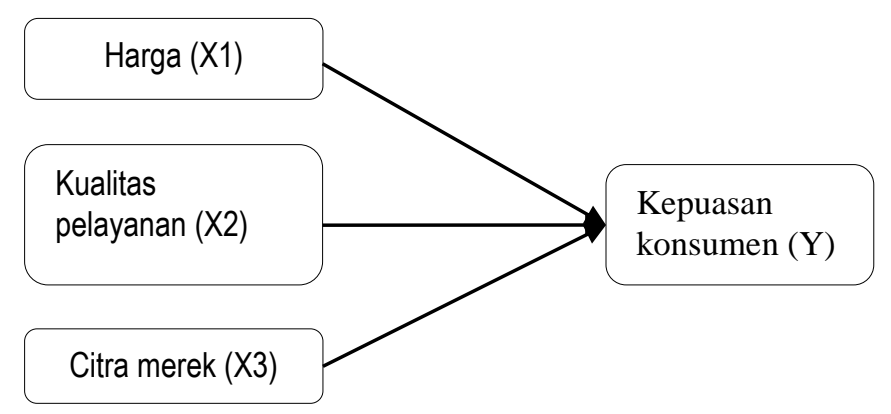

Metode

Adapun pengambilan sampel dalam penelitian ini menggunakan purposive sampling, karena peneliti menggunakan pertimbangan sendiri pada saat melakukan pengambilan sampel. Populasi dalam penelitian ini adalah semua pelanggan yang datang membeli dan menikmati kopi spesialty PT. Oro Kopi Gayo. Sampel pada penelitian ini adalah bagian dari populasi. Peneliti menggunakan teknik non probability sampling, pemilihan sampel dilakukan dengan cara memahami informasi yang diperlukan dan sesuai dengan kriteria yaitu konsumen yang menikmati kopi arabika spesialty lebihdari satu tahun baik di Pt.Oro Kopi Gayo maupun di luar perusahaan untuk. Pada penelitian ini maka peneliti akan menggunakan alat analisis struktural equation modeling.

Hasil

\section{Pengujian Validitas}

Pengujian validitas data dilakukan secara statistik dengan menggunakan program SPSS 20, yaitu dengan menggunakan Uji Pearson Product-Moment Coefecient of Correlation. Berdasarkan output komputer setelah dilakukan pengujian validitas seluruh pernyataan yang diajukan pada kuisioner sebanyak 16 item pertanyaan keseluruhannya adalah valid, sehingga seluruh pernyataan tersebut dimasukkan untuk pengujian selanjutnya. Nilai koefesien korelasi untuk pernyataan valid sudah lebih dari nilai kritis yaitu 0,146 ( lihat tabel $r$ ProductMoment untuk $n=180$ ).

\section{Pengujian Reliabilitas}

Penelitian ini akan menguji reliabilitas untuk mengetahui sejauh mana hasil yang telah diuji konsisten serta secara statistik yaitu dengan menghitung besarnya cronbach alpha dengan bantuan program SPSS 22,0 dan hasilnya bisa kita lihat pada tabel dibawah ini yang menunjukkan bahwa instrument yang diunakan dalam penelitian ini reliable karena nilai alpha lebih besar dari 0,60 (Malhotra,2005

Berdasarkan hasil reliabilitas pada tabel memiliki nilai alpha yang sangat baik dan di setiap variabel harga, kualitas pelayanan dan citra merek serta kepuasan pelanggan dinyatakan telah memenuhi persyaratan

\section{Proses dan Analisis Data}

\section{Analisis factor konfimator}

Index pengukuran TLI,CFI, CMI/DF dan RMSEA berada dalam rentang yang diharapkan meskipun AGFI dan GFI dibawah nilai yang telah ditetapkan. hal ini menunjukkan bawah tingkat sgnifikan sebesar 0,087 menunjukkan sebagai model persamaan yang baik.

Tabel 1. Indeks Pengujian Kelayakan Model

\begin{tabular}{|l|l|l|l|}
\hline Goodness Of Fit Index & Cut Of Value & Hasil analisis & Evaluasi model \\
\hline X2 chi square & Diharafkan kecil & 113.771 & Baik \\
\hline Significancy probability & $\geq 0,05$ & 0.462 & Baik \\
\hline RMSEA & $\geq 0,08$ & 0,06 & Cukup baik \\
\hline CMIN/DF & $\leq 2,0$ & 1.007 & Baik \\
\hline TLI & $\geq 0.95$ & 0.999 & Baik \\
\hline CFI & $\geq 0.95$ & 0.999 & Baik \\
\hline
\end{tabular}

Sumber: Data diolah, 2020 
Semua variabel harga, kualitas pelayanan, citra merek dan kepuasan pelanggan akan dilakukan analisis dengan menggabungkan semua 4 variabel yaitu harga 4 indikator, kualitas pelayanan 5 indikator, citra merek 4 indikator dan kepuasan pelanggan 4 indikator selanjutnya kita bisa melihat hasil analisis pada gambar dibawah ini :

Gambar 1. Analisis Factor Konfimatori Konstruk

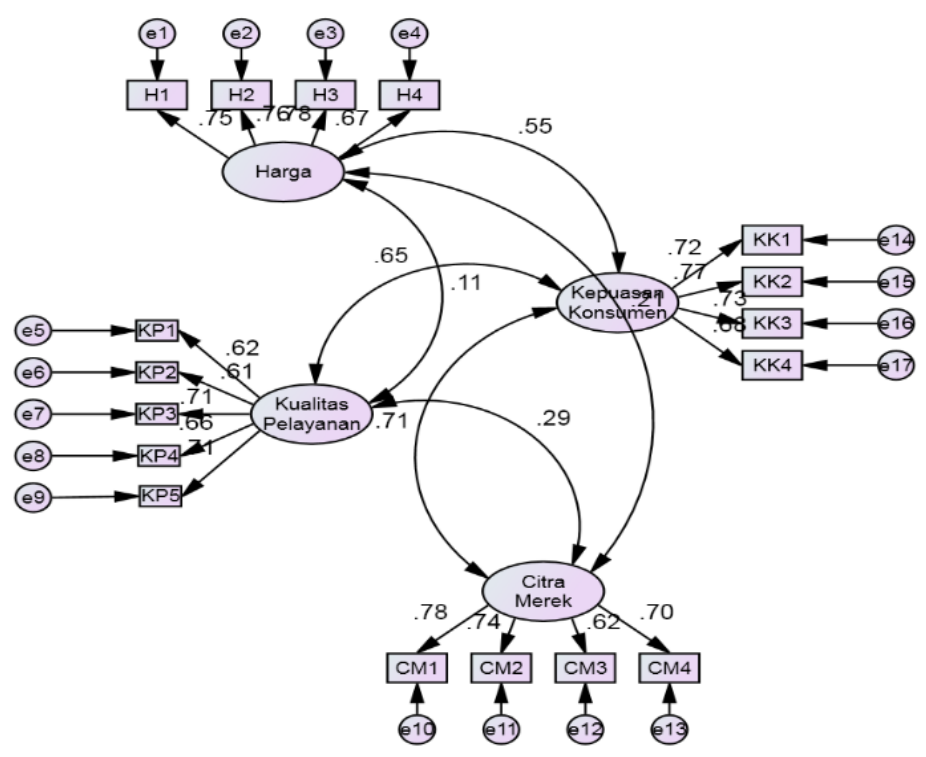

Semua indikator telah diikutsertakan dalam pengolahan data dan telah memiliki estimasi koefesien lebih besar 0,5 dan akan dilanjutkan dengan tahap struktural dan kelayakan model dengan melalui goodness of fit.

\section{Analisis Structural Equation Modeling (SEM)}

Uji statistik yang dilakukan peneliti dengan tahap full model dengan uji kesesuaian dapat dilihat pada gambar di bawah ini :

Gambar 2. Hasil pengujian structural equation modeling

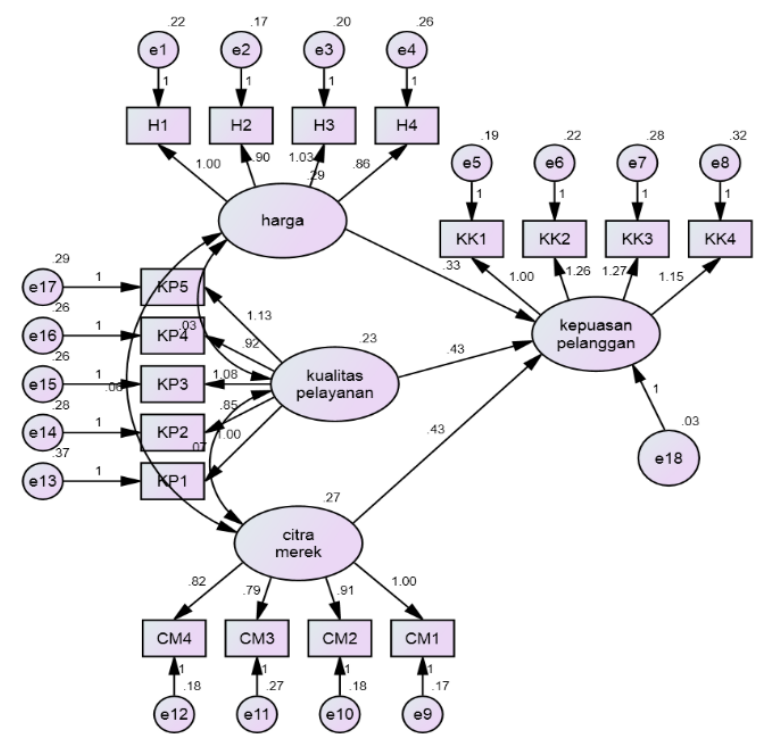




\section{Hipotesis}

Setelah terpenuhinya semua asumsi, maka akan dilakukan pengujian hipotesis yang dilakukan berdasarkan nilai critical ratio (cr) dari suatu hubungan kausalitas dari hasil olah data SEM structural equation modeling) dapat dilihat pada tabel di bawah ini :

Tabel 5 Regression Weights Structural Equation Modeling

\begin{tabular}{|l|l|l|l|l|l|}
\hline \multicolumn{1}{|c|}{ Variabel X } & \multicolumn{1}{c|}{ Variabel Y } & estimate & S.E.. & .CR & P \\
\hline Harga & Kepuasan Pelanggan & .332 & .059 & 5.634 & ${ }^{* * *}$ \\
\hline Kualitas Pelayanan & Kepuasan Pelanggan & .429 & .078 & 5.500 & ${ }^{* * *}$ \\
\hline Citra_Merek & Kepuasan Pelanggan & .433 & .069 & 6.309 & ${ }^{* * *}$ \\
\hline
\end{tabular}

Sumber: Data primer diolah, 2020

\section{Pembahasan}

\section{H1. Pengaruh Harga terhadap Kepuasan Pelanggan}

Harga menjadi sebuah variabel yang harus digunakan oleh Perusahaan untuk mendapatkan keuntungan besar dan memberikan kesetiaan pada konsumen sehingga pengaruh harga terhadap kepuasan pelanggan mencapai nilai cr sebesar 5,634 dan probabilitas 0,000. Maka kita bisa melihat nilai cr lebih kecil dari nilai $t$ tabel sebesar 1,97 dengan probabilitas lebih kecil dari 0,05. Dimana Perusahaan harus lebih meningkatkan kualitas produk sehingga walaupun harga yang diberikan terlalu tinggi namun produk yang didapakan sesuai dengan yang diharapkan pelanggan.

\section{H2. Pengaruh Kualitas Pelayanan terhadap Kepuasan Pelanggan}

Setelah kita mengetahui bahwa adanya pengaruh kulitas pelayanan terhadap kepuasan pelanggan, maka kita bisa melihat nilai parameter (cr) sebesar 5.500 dan dengan probabilitas lebih kecil dari 0,05 . Sehingga peneliti mengambil kesimpulan bahwa Perusahaan harus memiliki karyawan yang mampu memberikan pelayanan yang layak diterima oleh konsumen agar pelanggan tidak merasa jenuh ketika selalu melakukan pembelian produk di Perusahan PT.Oro Kopi Gayo dan ini memberikan dampak yang sangat positif terhadap kepuasan pelanggan.

\section{H3. Pengaruh Citra Merek terhadap Kepuasan Pelanggan}

Citra merek sudah menjadi salah satu varibel utama dalam meningkatkan penjulan sebuah produk, dengan nilai critical rasio (cr) 6,309 dangan probabilitas 0,000 dan nilai cr lebih besar dari nilai t tabel sebesar 1,97 dan probalilitas lebih kecil dari 0,05 dari tersebut kita bisa melihat bahwa citra merek sudah sangat dibutuhkan oleh sebuah Perusahaan agar Perusahaan tetap berjalan dengan baik dan mempunyai dampak positif terhadap kepuasan konsumen yang telah melakukan pembelian barang dan jasa.

\section{Kesimpulan}

Hasil penelitian tersebut, dapat kita ambil kesimpulan bahwa variabel yang digunakan untuk melihat kepuasan pelanggan sebuah Perusahaan yaitu harga, kualitas pelayanan, citra merek sangat mempunyai pengaruh positif terhadap kepuasan pelanggan dan pelanggan akan sangat loyal ketika perusahaan memberikan harga yang sesuai dengan kualitas produk, layanan yang diberikan maksimal dan merek yang digunakan sebagai penyampaian produk yang berkualitas sehinggan Perusahaan akan mendapat keuntungan yang besar. dalam penelitian mempunyai keterbatasan para pelanggan yang benar-benar memahami bagaimana kualitas kopi specialty yang mereka konsumen, mereka hanya berpendapat dari pengalaman sehari-hari oleh karena itu perlunya para peneliti meneruskan penelitian ini lebih mendalam.

\section{Daftar Pustaka}

Aaker, David. (2012). Building strong brands. New York: The Free Press..

Abdullah, Thamrin Dan Francis Tantri. 2010 Manajemen Pemasaran, Jakarta : PT.Raja Grafindo Persada

Bellezza,S.,Keinan,A. (2014), Brand Tourist: Hownon Core Users Enhance The Brand Image By Eliciting Pride. Journal Of Consumer Research, 41(2),397-417.

Cengiz, Emrah. 2010. Measuring Customer Satisfaction: Must Or Not?. Journal Of Naval Science And Enginering, 6(2):76-88.

Coelho, P.S., \& Henseler, J.(2012).Cerating Customer Loyalty Through Service Customization European Journalof Marketing, 46, 331-356. 
Fiazisyah, a.(2018). Pengaruh Kualitas Produk, Harga, Dan Kualitas Pelayanan Terhadap Kepuasan Konsumen Restoran Cepat Saji Kfc Basuki Rahmat Surabaya, e-jurnal boga, Volume 7 No. 02, 168-187

Ferrinadewi, Erna. 2008. Merek dan Psikologi Konsmen: Implikasi Pada Strategi Pemasaran. Edisi pertama. Yogyakarta: Graha IImu

Guzzo, R,2010. Customer Satsifactin In The Hotel Industry : A Case Study From Sicily,International Journal Of Marketing Studies, Vol.2.No.2.

Heryanto, Imam. 2015. Analisis Pengaruh Produk, Harga, Distribusi, dan Promosi terhadap Keputusan Pembelian serta Implikasinya pada Kepuasan Pelanggan. Jurnal Ekonomi, Bisnis \& Entrepreneurship. Vol. 9 No. 2.

Ha, J. and Jang, S.C., 2010," Perceived Value, Satisfaction, and Behavioral Intention: Role of Familiarity in Korean Restaurants ", International Journal of Hospitality Management, Vol. 29, pp. 2-13.

Gronroos, C. (2001). The perceived service quality - a mistake?. Managing Service Quality, 11(3), 150-152.

Heung, V. C. S., \& Gu, T. (2012). Influence of restaurant atmospheric on patron satisfaction and behavioral intentions. International Journal of Hospitality Management, 31, $1167 \pm 1177$. Doi:10.1016/j.j.jhm.2012.02. 004.

Hsieh, M. H. , Pan, S. L. , \& Setiono, R. (2004). Product, corporate, and country-image dimensions and purchase behavior: a multicountry analysis. Journal of the Academy of Marketing Science, 32(3), 251 \pm 270

Irawan, handi, 2008, membedah strategi kepuasan konsumen, cetakan pertama : PT. Gramedia, Jakarta

Komalig, Anastasya L. 2013. Customer Relationship Management and the Effect of Promotion on Debtor Satisfaction at PT. Bank of North Sulawesi, Manado's Calaca Branch. EMBA Journal vol.1 no.4 December 2013.

Kotler, Philip., dan Kevin Lane Keller. 2009. Manajemen Pemasaran. Edisi 13. Jilid 2. Alih bahasa: Bob Sabran. Jakarta : Penerbit Erlangga

Kotler, P. \& Armstrong, G. (2012), Prinsip- Prinsip Pemasaran Edisi 12 penerbit Erlangga

Kotler, Philip. 2008. Manajemen Pemasaran Edisi 12 Jilid 2. Jakarta: Indeks

Lemmeryinen, a, dimitrovski,d, nieminen, I., pohjola, $t$ (2016), cruise destination brand awarenes as a moderator in the relationship of motivation satisfaction tourism review, 71(4),245-258.

Mohajerani, P., dan Miremadi, A. 2012. Customer sat isfact ion modeling in hotel industry: A case st udy of Kish Island in Iran. International Journal of Marketing Studies, 4(3), 134-152.

Malhotra. 2005. Riset Pemasaran. Jilid I. Edisi 4. Jakarta: Indeks Kelompok Gramedia.

Riggs, H.E.(2001), The Price Of Perception The New York Times.

Renneboog, L.,Spaenjers, C.(2013), Buying Beaty: About Prices Dan Return In The Art Market. Management Science, 59(1),36-53

Rondonuwu, Priscilia D. 2013. Kualitas Produk, Harga dan Kualitas Layanan Mempengaruhi Kepuasan Pelanggan Pengguna Mobil Nissan March di PT. Wahana Wirawan Manado. Jurnal EMBA vol.1 no.4 Desember 2013.

Rizan, M.,Warokka, A., Listyawati, D (2014), Relationship Marketing And Customer Loyalty : Are Customer Satisfaction And Customer Trust Really Used As Intervening Variables ? Journal Of Marketing Research And Case Studies, 2014.1-12.

SU, J., Tong, X.(2015), Brand Personality And Brand Equity : Evidence From The Sport Swear Industry. Journal Of Product And Brand Management, 24(2), 124-133

Sang HK (2009). The influence of emotional intelligence on salesperson behavior and perceptions of customer service quality. Afr. J. Bus. Manage., 4 (11): 2343-2353.

schneider, Benjamin \& White, Susan S. 2004. Service Quality: Research Perspective. SAGE Publications

Suyanto,M. 2007. Marketing Strategy. Andi offset, Yogyakarta.

Sangadji, Etta Mamang dan Sopiah, 2013. Perilaku Konsumen. Yogyakarta : Andi Offset

Schiffman dan Kanuk. 2008. Perilaku Konsumen. Jakarta: Indeks.

Suryani, Tatik 2013. Perilaku Konsumen di Era Internet. Implikasinya pada Strategi Pemasaran. Edisi Pertama. Cetakan Pertama. Graha Ilmu. Yogyakarta.

Suryati, L., Krisna, N.L. (2015), Determinan Kepuasan Pelanggan dan Implikasinya Terhadap Loyalitas Pelanggan (Studi Empiris Pelanggan Otomotif di Medan). Jurnal Internasional Bisnis Terapan dan Penelitian Ekonomi, 13 (7), 5045-5066 
Tjiptono, Fandy. 2011. Strategi Bisnis Pemasaran. Yogyakarta: Andi Tjiptono Fandy, 2015, Strategi Pemasaran, Edisi 4, Andi, Yogyakarta

Weenas, Jackson R.S. 2013. Kualitas Produk, Harga, Promosi, dan Kualitas Layanan Mempengaruhi Keputusan Pembelian Spring bed comporta. Jurnal EMBA vol.1 no.4 Desember 2013.

Xia, Wang., Jie, Zhang., Chaolin, G \& Feng, Zhen. (2009). Examining Antecedents and Consequences of Tourist Satisfaction: A Structural Modeling Approach. Tsinghua Science and Technology. 14, No. 3. 397-406.

$\mathrm{Yu}$, Yi-Ting and Dean, Alison (2001), "The contribution of emotional satisfaction to consumer loyalty," International Journal ofService Industry Management, Vol. 12 No. 3/4, pp. 234-250.

Yang Yu Ren (2006). The research of the server industry brand image. The Fu Ren University. Unpublished Master's thesis.

Zhang, X Dan Tang, Y.,2006. Customer Understand E-Service Quality In Online Shopping. Master's Thesis, Marketing Of The Lulea University Of Technologi

Zhang, Y.(2015), The Impact Of Brand Image On Consumer Behavior. A Literature Review. Open Journal Of Busines And Management.3(1),58-62). 